\title{
Towards a self-deploying and gliding robot
}

Mirko Kovac, Jean-Christophe Zufferey and Dario Floreano

\begin{abstract}
Strategies for hybrid locomotion such as jumping and gliding are used in nature by many different animals for traveling over rough terrain. This combination of locomotion modes also allows small robots to overcome relatively large obstacles at a minimal energetic cost compared to wheeled or flying robots. In this chapter we describe the development of a novel palm sized robot of $10 \mathrm{~g}$ that is able to autonomously deploy itself from ground or walls, open its wings, recover in midair and subsequently perform goal-directed gliding. In particular, we focus on the subsystems that will in the future be integrated such as a $1.5 \mathrm{~g}$ microglider that can perform phototaxis; a $4.5 \mathrm{~g}$, bat-inspired, wing folding mechanism that can unfold in only $50 \mathrm{~ms}$; and a locust-inspired, $7 \mathrm{~g}$ robot that can jump more than 27 times its own height. We also review the relevance of jumping and gliding for living and robotic systems and we highlight future directions for the realization of a fully integrated robot.
\end{abstract}

\section{Introduction}

Small robots face big problems when it comes to locomotion in natural and rough terrain. This is usually referred as the "Size Grain Hypothesis" [26], which is described as an "increase in environmental rugosity with decreasing body size". In the animal kingdom, there are many animal species that master locomotion in rough terrain very well by using a combination of different locomotion modes, such as jumping and subsequent gliding flight. This allows them to minimize energetic cost of transport, overcome large obstacles, escape predators and reduce the potentially hazardous impact forces on landing.

Examples of animals that combine self-deployment with gliding can be found in many different species with different evolutionary origins. Spiders, locusts, gliding

Laboratory of Intelligent Systems, EPFL, Lausanne, Switzerland, e-mail: Mirko.Kovac@epfl.ch, Jean-Christophe.Zufferey@epfl.ch, Dario.Floreano@epfl.ch 
ants, bats, gliding mammals, gliding lizards, flying snakes, gliding geckoes, flying fish, flying squids and many birds use combinations of jumps and gliding flight. Gliding can also be found amongst extinct animals species such as the Sharovipteryx and some lizard like reptiles with similar wings to the Draco lizard. See figure 1 for an overview and references on animals that use gliding as part of their locomotion strategy.

It also has been argued [19][18][34][10] that gliding may have been the precursor to flapping flight in insects and vertebrates due to its simplicity.

As the focus of this chapter is of technological nature, the reader may be referred to [51][18][5][40] for in-depth reviews of self-deploying and gliding animals with detailed description of morphology and behavior. Important here to mention however is that these animals barely use steady-state gliding, but change their velocity and angle of attack dynamically during flight. This increases the gliding ratio, which is defined as the horizontal distance traveled per unit height loss, or allows the animal to precisely land on a spot, such as perching on a tree branch.

The combination of jumping and gliding is also interesting for miniature robots because it allows them to overcome larger obstacles compared to wheeled and legged robots at the same scale and because it requires less energy compared to flying robots of similar size. In this chapter, we describe our project on the development of a palm-sized microglider of around $10 \mathrm{~g}$ that possesses the ability to autonomously self-deploy from ground or walls, open its wings, recover from any position in mid-air and perform goal directed gliding.

To date, there have been very few attempts to build robots that combine terrestrial and aerial locomotion.

Armour et al. [4] recently presented a $700 \mathrm{~g}$ jumping robot of octahedral shape with wing like structures to reduce the impact force on landing. This design is able to clear heights of up to $1.17 \mathrm{~m}$ but the addition of the wings actually reduces the range of the jump instead of extending it.

A related project with similar aims is the so called long-jumping "Grillo" mini robot [46]. Prototypes presented so far range in mass between 8 and $80 \mathrm{~g}$ and can jump obstacles of approximately $5 \mathrm{~cm}$ of height.

Another recent development which is also described in chapter 18 of this book is a hybrid sensory platform [8] that can crawl using "whegs", a combination of wheels and legs, fold its wings to enter narrow spaces and perform propelled flight after dropping down from roofs. Its weight is approximately $100 \mathrm{~g}$, with a wingspan of $30.5 \mathrm{~cm}$. It possesses flexible wings as a passive damping mechanism to deal with wind gust, but no quantitative characterization of its efficiency has been presented so far. A limitation of this flying platform is its relatively high weight per unit wing area which necessitates $6.6 \mathrm{~m}$ height loss for recovery after dropping down from roofs for the transition to propelled flight. To date, this transition has been shown only when the airplane is dropped along the major axis of the fuselage.

Summarizing, only a few projects address the importance of hybrid locomotion as an efficient way of moving in rough terrain, and none has yet successfully integrated jumping and gliding to overcome large obstacles and reduce the energetic cost of transport. 
In the following sections we will present our first steps towards the creation of a self deploying microglider. We start by outlining miniaturization and efficiency of gliding and the development of a gliding robot. We then proceed to investigate mechanisms for wing folding and rapid deployment, describe the prototype of a jumping microrobot and conclude with a discussion of how to integrate it with the gliding system.

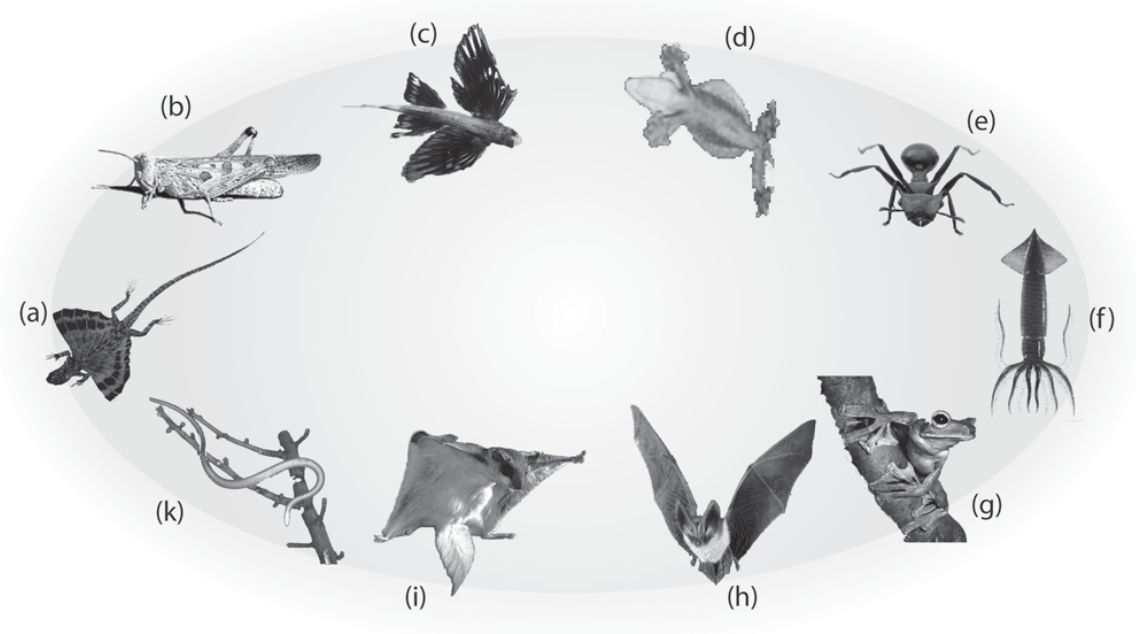

Fig. 1 A selection of animals that use gliding as part of their locomotion strategy. (a) gliding lizards [41][37][36][31], (b) locusts [45], (c) flying fish [17][5], (d) gliding geckoes [25][59], (e) gliding ants and spiders [57][58][50][16], (f) gliding squid [32][5], (g) gliding frogs [35][20], (h) bats [52], (i) gliding mammals [38][42][7][15], (k) gliding snakes [48][47].

\section{Gliding in robotics}

Wood et. al. recently presented a remarkable $2.2 \mathrm{~g}$ microglider [56] that has been specifically designed for gliding flight. It uses a four-bar piezo actuator for rudder deflection and is intended to avoid obstacles using optical flow. Although this realization is a master piece of micromechatronics, no characterization of autonomous flight control has been provided so far. Its relatively high flight velocity of more than $5 \mathrm{~m} / \mathrm{s}$ largely limits its applicability in tight environments as it requires a turning radius of $8 \mathrm{~m}$ to perform a U-turn [21].

As a first step towards our self deploying microglider, we developed a $1.5 \mathrm{~g}$ gliding robot [29] (figure 2) that can perform phototaxis, similar to the ground vehicles as proposed by Breitenberg [9]. To the best of our knowledge, this microglider is the lightest autonomously flying system to date. In order to achieve this very low 
weight, we opted for a relatively new kind of steering system. We developed a $0.2 \mathrm{~g}$ Shape Memory Alloy (SMA) actuator that is harmoniously integrated into the structure of the microglider and allows for direct control of the rudder. As for navigation, two tiny photoreceptors and a simple control strategy were used to detect and follow light gradients.

\subsection{Airframe, sensing and actuation}

The goal of the mechanical airframe design is to reduce the weight as far as possible while keeping the structure simple and easy to produce. As in our indoor flying robots [60], also described in chapter 6 of this book, we chose to use carbon fiber material for the fuselage, the wing frame and the rudder (figure 3). The material of the wing surface is biaxially-oriented Poly Ethylene Terephthalate (boPET) film (trade name "Mylar foil") chosen for its high tensile strength. This construction principle leads to an airframe weight of only $0.31 \mathrm{~g}$ and has the advantage of being slightly flexible and thus being able to better absorb landing impact forces without breaking. A complete overview of the weight budget is shown in table 1 .

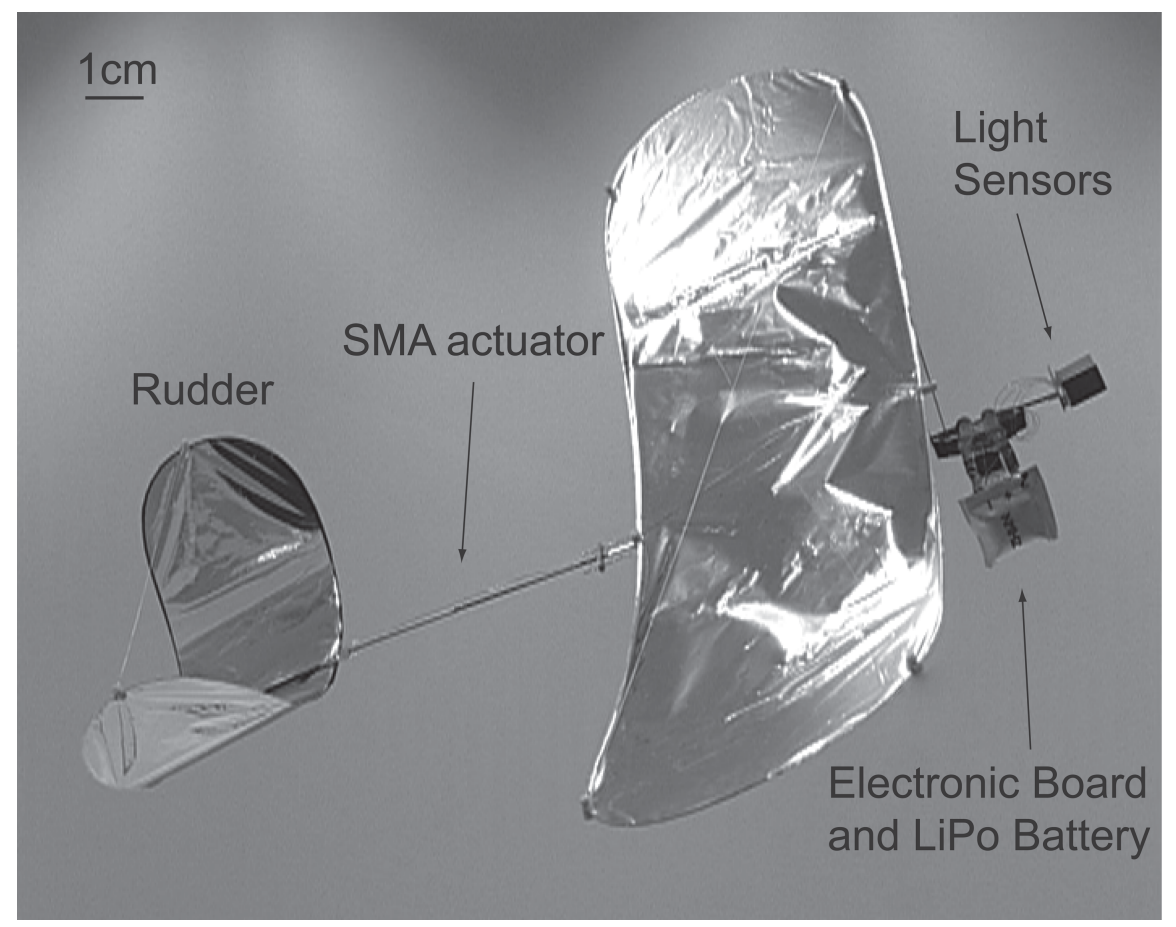

Fig. $21.5 \mathrm{~g}$ SMA-actuated microglider performing autonomous phototaxis with a wingspan of $24 \mathrm{~cm}$, a length of $22 \mathrm{~cm}$, capable of flying at $1.5 \mathrm{~m} / \mathrm{s}$. 


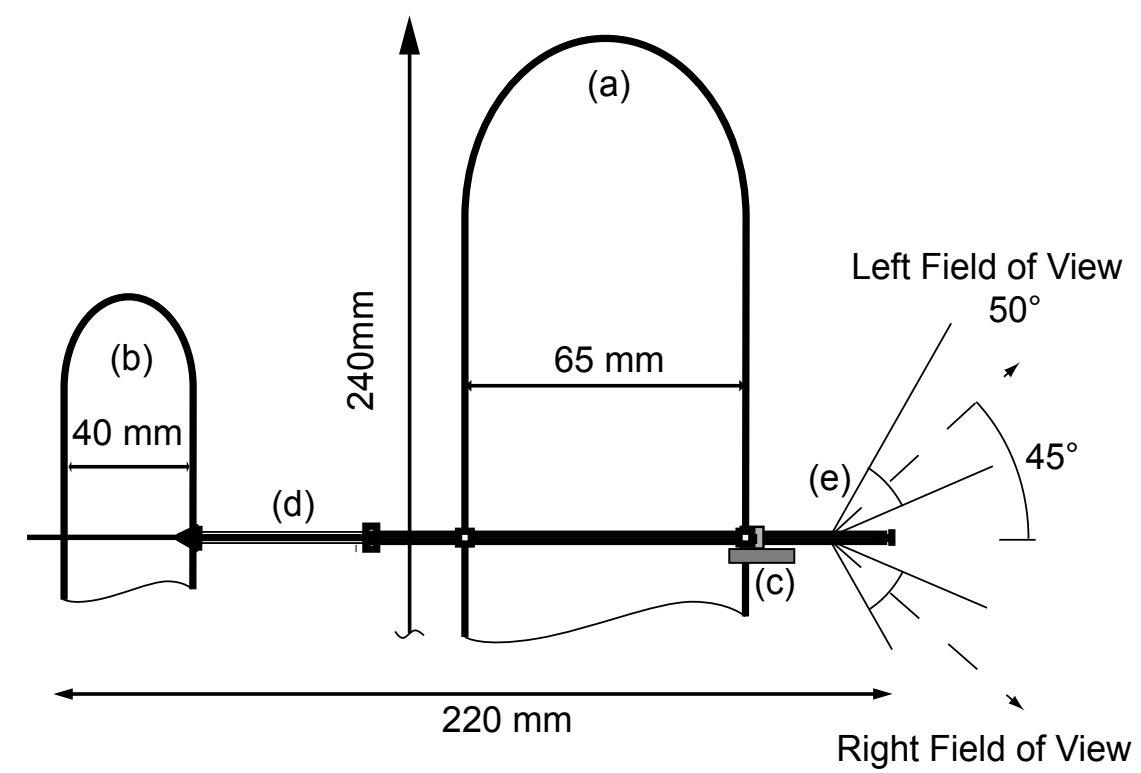

Fig. 3 Construction plan of the microglider. (a) main wing, (b) rudder, (c) electronic board and battery, (d) SMA actuator, (e) light sensors.

Table 1 Weight budget of the microglider

\begin{tabular}{|c||c|}
\hline Part & Mass $(\mathrm{g})$ \\
\hline \hline Electronic board & 0.33 \\
\hline Battery 10 mAh & 0.55 \\
\hline Fuselage & 0.18 \\
\hline Front wing & 0.1 \\
\hline Rudder & 0.03 \\
\hline Light sensors & 0.1 \\
\hline SMA actuator & 0.2 \\
\hline Cables and soldering & 0.02 \\
\hline \hline Total mass & $\mathbf{1 . 5 1}$ \\
\hline
\end{tabular}

As for the actuation system, different designs and materials could potentially be employed for actuating the control surfaces, such as magnetic coils, piezo actuators, 

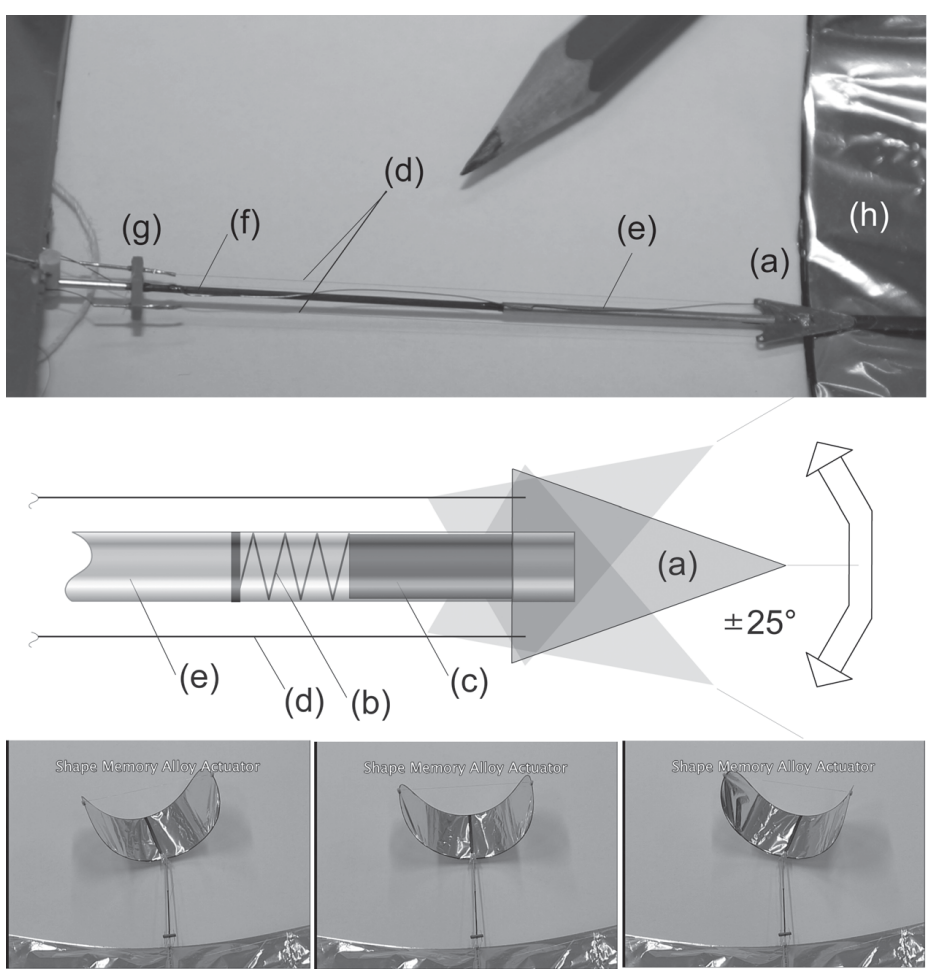

Fig. 4 SMA actuator, (a) horn, (b) spring, (c) piston, (d) SMA wire, (e) steel tube, (f) carbon fuselage, $(\mathrm{g})$ frame with electrical interface to the electronic board, (h) rudder. A PWM signal from the microcontroller heats up the SMA wire on one side. Due to the crystalline structure change this wire contracts and bends the rudder to one side.

Table 2 Actuator comparison

\begin{tabular}{|l||l|l|l|l|l|l|}
\hline $\begin{array}{l}\text { Actuator } \\
\text { type }\end{array}$ & Mass $(\mathrm{g})$ & $\begin{array}{l}\text { Drive Elec- } \\
\text { tronics }(\mathrm{g})\end{array}$ & Power $(\mathrm{mW})$ & $\begin{array}{l}\text { Commercial } \\
\text { availability }\end{array}$ & $\begin{array}{l}\text { Mechanical } \\
\text { complexity }\end{array}$ & Force output \\
\hline $\begin{array}{l}\text { Magnetic } \\
\text { coils [2] }\end{array}$ & 0.15 & 0.02 & 180 & +++ & ++ & - \\
\hline Piezo [56] & 0.05 & 0.2 & 7 & + & - & +++ \\
\hline SMA [27] & 0.12 & 0.01 & 171 & + & + & ++ \\
\hline
\end{tabular}

(++ + : very favorable; - - - : very unfavorable) 
or SMA's. Table 2 compares three types of actuators used on airplanes of less than $10 \mathrm{~g}$.

Small magnetic coils are easily available on the market, but deliver comparatively smaller forces and are difficult to control precisely in position. Piezo materials, on the other hand, deliver relatively high forces at very low power consumption, but are limited in displacement and usually require a relatively sophisticated and careful fabrication process and mechanical design. In addition to the actuator itself, the need for relatively heavy electronics to reach the required high voltage $(200 \mathrm{~V}$ in [56]) decreases the promising properties of this approach for actuation. Therefore, we decided to use thin SMA wires because of their simplicity, high power density and comparatively large displacement of 5\% of their length. For our application of rudder control, we used commercially available Nickel Titanium Alloy (Nitinol) wire, also known as "Muscles Wire" [1].

The working principle of SMA wire is that it exploits the crystallographic structure change of Martensite to Austenite (thermoelastic martensitic transformation) when heated above the transition temperature. This phase change produces a comparatively high force that can be used for actuation. A well known drawback of SMA in general is its relatively high power consumption. However, for thin wires of $25 \mu \mathrm{m}$ diameter, the power consumption is only $160 \mathrm{~mW}$, which is comparable to small magnetic actuators.

The actuator we developed consists of (figure 4, a) a Copper-Beryllium horn, (figure 4 , e) a $0.7 \mathrm{~mm}$ steel tube, (figure $4, \mathrm{~g}$ ) a frame with electrical interface and (figure 4, d) two $25 \mu \mathrm{m}$ SMA wires attached to the frame and the horn. The stability of the actuator is given by the carbon fuselage (figure 4, f). The wires are activated with a Pulse Width Modulation (PWM) signal, which leads to a maximal force of $0.069 \mathrm{~N}(\hat{=} 7 \mathrm{~g})$ at the attachment point of the horn. This leads to a deflection of the horn and of the rudder, which is glued on the horn. The rotation point is the attachment point of the other SMA wire and the counterpart of this movement is the custom made brass spring (figure $4, b$ ), which ensures back alignment of the rudder to the neutral position at zero PWM duty cycle.

This actuator is then integrated with the airframe, a PIC 16 microcontroller, two light sensors and a simple proportional control strategy [29], which enables the microglider to autonomously detect and follow light gradients as shown in figure 5. Launched from a catapult device to provide the glider with a take-off velocity of $2 \mathrm{~m} / \mathrm{s}$, it displays a gliding ratio of 5.6, which is relatively high compared to many gliding animals at such small scales. In order to characterize its phototaxis capabilities, we carried out three series of launches, each with a different position of the light bulb and showed that the glider consistently lands near the light source (figure $5)$. 


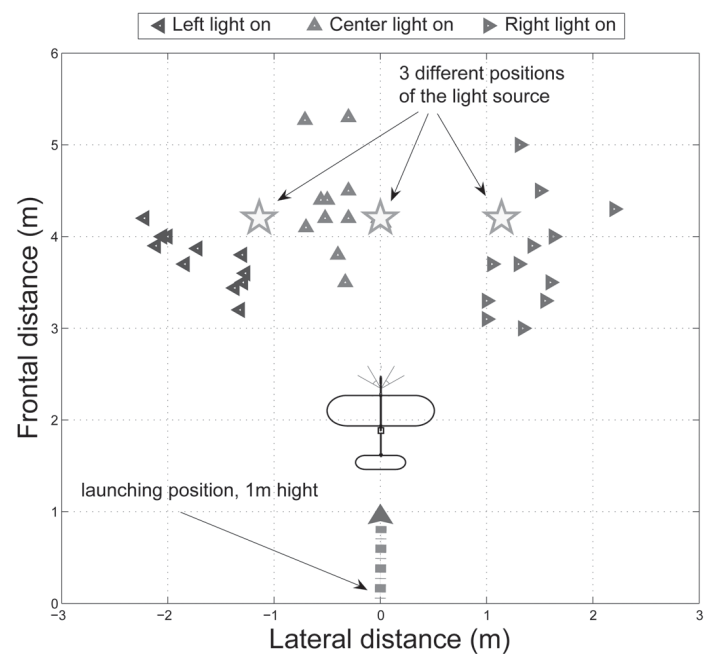

Fig. 5 Top view of the setup for the phototaxis experiments. Stars indicate the three possible light source locations. For each of the three locations, 12 subsequent launches have been carried out. The triangles mark the landing positions.

\subsection{Wing folding}

The technology described above is promising for a small jumping robot, but the fixed open wings offer too much resistance to the air during the deployment phase of the jump. In order to maximize the jump height, the exposed wing surface has to be as small as possible during deployment. We thus aimed at developing a wing folding mechanism that keeps the wings contracted while the robot is in the deployment phase and quickly unfolds them when the robot starts to lose altitude. The requirements for such a mechanism are to be able to open very quickly, be as light weight as possible, stable when open and robust enough to withstand eventual crash landings.

Nature offers many foldable structures, which are a potential source of inspiration for the design of such a mechanism. For example, leaves unfold from a very compact package to the complete unfolded leaf with a high structural stability [33][43]. Other ways of unfolding can be found in soft animals, such as anemones and various worms [55][53]. Also, many insects use Origami-like mechanisms to fold their wings, such as the hind wings of Dermaptera [23][24], and most of birds and bats fold wings to protect their often fragile structures. Figure 6 shows some examples of folding structures found in nature.

Origami-like structures are very interesting and when carefully designed, would even allow to unfold in a three dimensional shape and form a cambered wing (similar as the wooden roof structures in [12], see figure 6). A difficulty for this technology however is to find an appropriate material that is light enough and can be used on such small scales. After a detailed evaluation phase of all those solutions 
and several conceptional prototypes, we decided to adopt an abstracted form of the wing folding principle used by bats. The main advantages of this solution are its structural stability when open and the possibility to easily build the skeleton out of carbon and cover the wing itself with Mylar foil so as to yield a minimal weight. The realized prototype (figure 7) weights only $4.5 \mathrm{~g}$ and is able to unfold its wings in $50 \mathrm{~ms}$ on command using a SMA based locking mechanism.

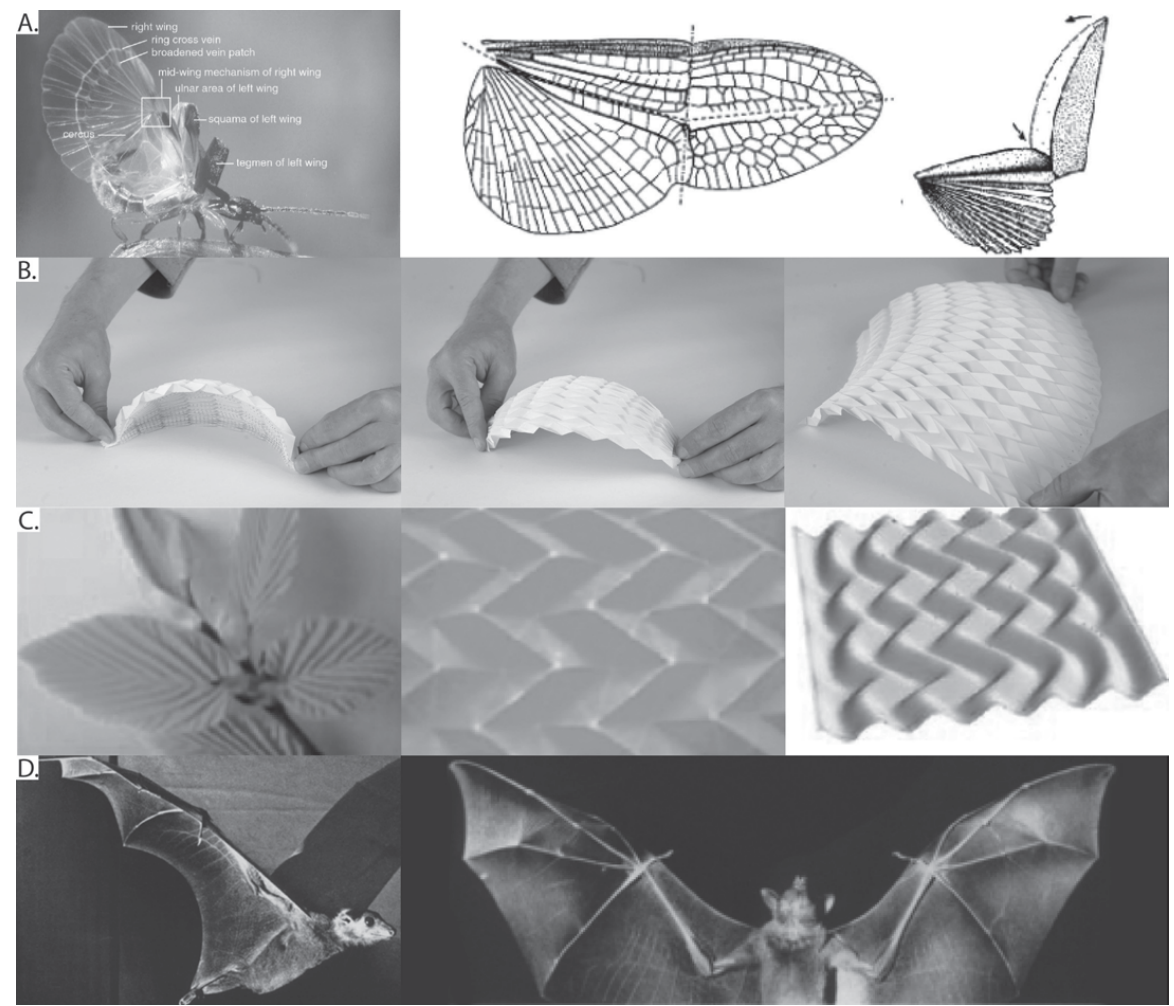

Fig. 6 A selection of folding structures. A: Hind wings of Dermaptera [23][24]; B: Model of a wooden roof structure [12]; C: Folding leafs [33]; D: Wing folding in bats [39].

The skeleton of the wing folding mechanism consists of six hinges that are interconnected with $1 \mathrm{~mm}$ carbon rods and covered with Aluminium coated $5 \mu \mathrm{m}$ Mylar foil (Fig. 7). The folding of the wings happens by rolling up a string (a) which is attached at the tip of the wing (b). The hinges contain each a torsion spring that is encapsulated in a Polyoxymethylene (POM) frame (figure 9). By rolling up the string, the torsion springs store elastic energy and unfold the wing once the string gets released. A complete unfolding sequence takes only $50 \mathrm{~ms}$ and can be seen in figure 8. In order to roll up and release the string, we developed a SMA based unlocking mechanism, which will be described next. 

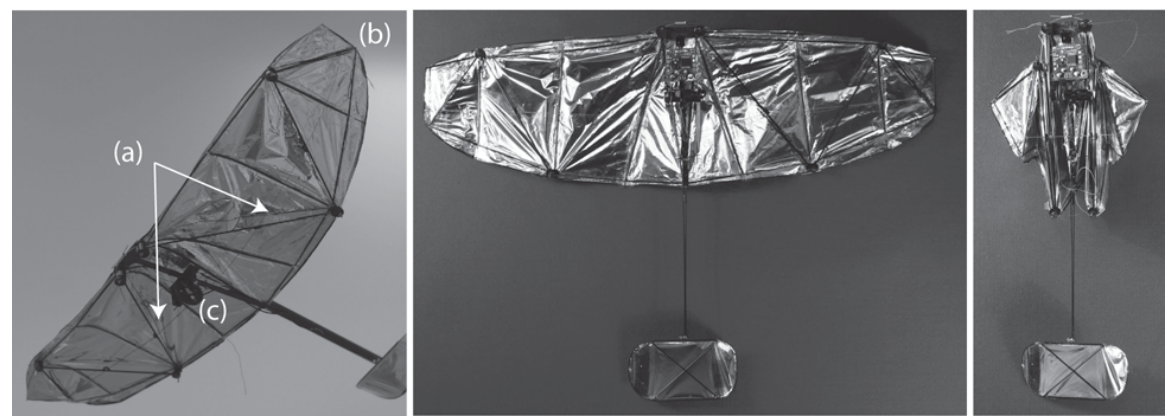

Fig. 7 Bat inspired wing folding system. A string (a) is attached to the wing tips (b) and is rolled on a spool (c) to fold the wing.

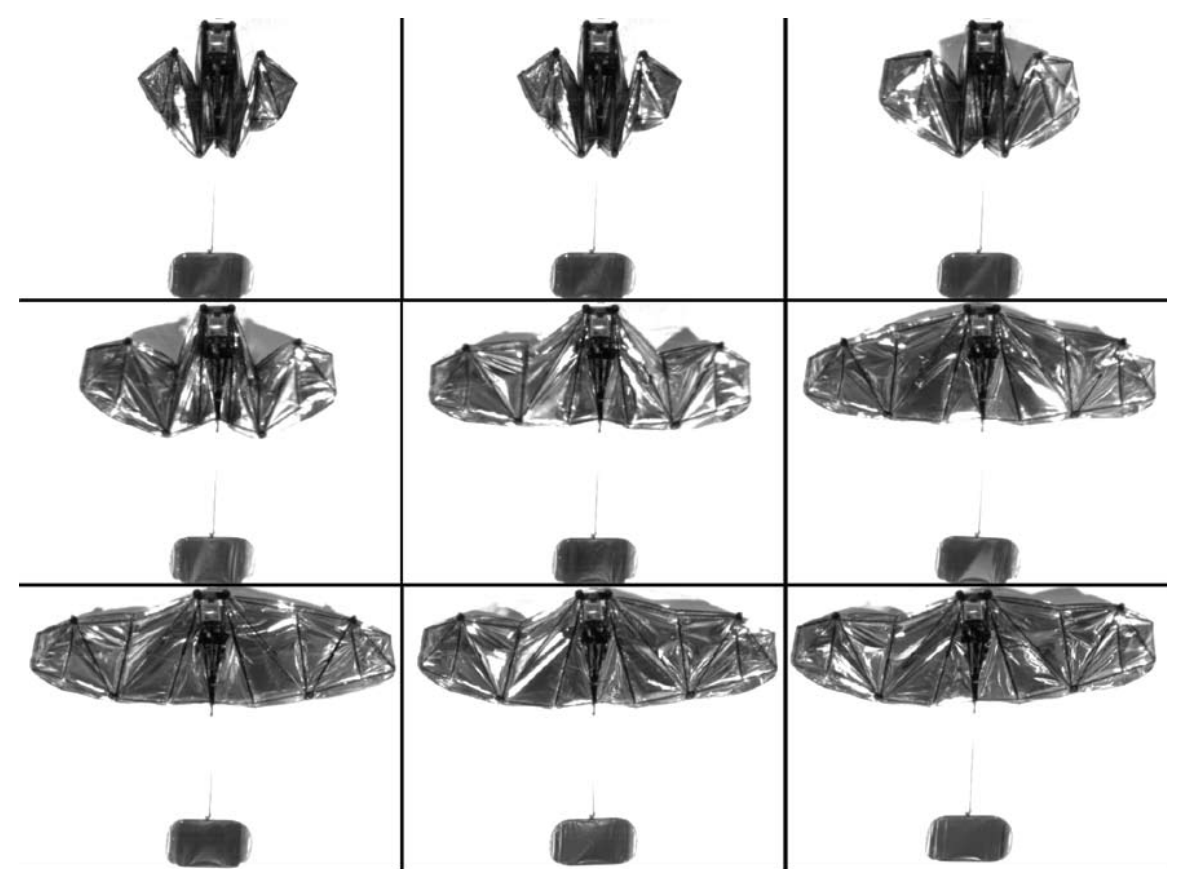

Fig. 8 A complete unfolding sequence takes only $50 \mathrm{~ms}$.

In order to fold the wing, the string (Figure 10, a) that is attached to the wing tip is rolled on the spool (Figure 10, b). The spool itself is connected to a gear (Figure 10, c) which is interfaced with the gearbox of the jumping mechanism as we will describe later in section 4. A $37 \mu \mathrm{m}$ SMA wire (Figure 10) contracts and pulls the spool laterally, to unlock it from the gear and thus allows the force stored in the torsion springs in the hinges of the wings to unfold the wings. As soon as the unfolding is completed, the spring (Figure 10, d) pushes the spool back and 


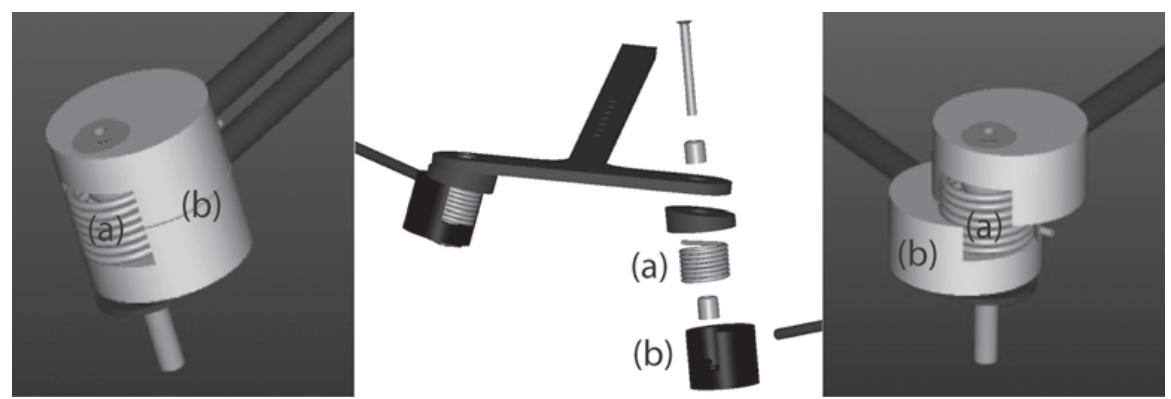

Fig. 9 The wing folding mechanism contains six hinges which are interconnected with carbon rods. The torsion spring (a) is embedded in a POM frame (b).

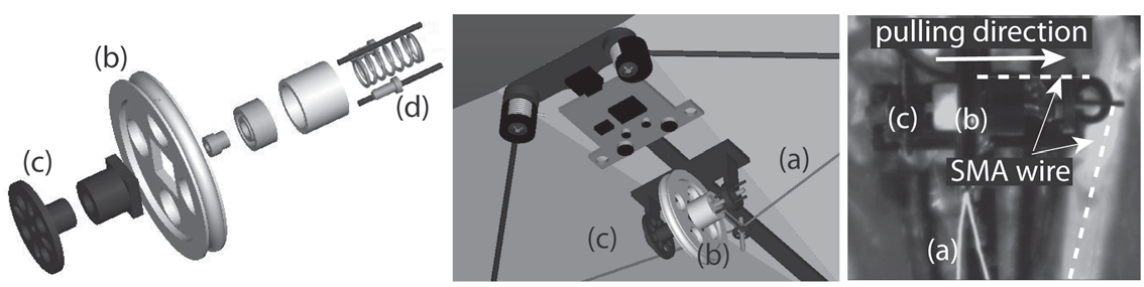

Fig. 10 SMA based release mechanism. The string (a) is attached to the wing tip and gets rolled up on the spool (b), which is connected to the gear (c). A $37 \mu \mathrm{m}$ SMA wire pulls the spool laterally to unlock it from the gear and to allow the wing to unfold. After relaxing the SMA, the spring (d) pushes the spool back and connects it with the gear for the next folding cycle.

reconnects it with the gear (Figure 10, c) in order to fix the position and allow the next folding sequence.

\section{Jumping}

The jumping mechanism must be light weight and capable of propelling the glider as high as possible into the air. Table 3 summarizes the performance of existing jumping robots with onboard energy and control. None of these systems are sufficient to meet the weight and size constrains of our self deploying microglider, i.e. palm sized with an entire system weight of $10 \mathrm{~g}$. We thus developed a $5 \mathrm{~cm}$ jumping mechanism [28] (figure 11 and 12) weighting a mere $7 \mathrm{~g}$ with electronics and battery. It consists of the gearbox including motor, gearwheels and cam, the main leg, carbon rods as feet, the infrared receiver and a $10 \mathrm{mAh}$ Lithium Polymer battery. Its design allows to manually adjust the take-off angle, jumping force and force profile during the acceleration phase. This is useful to obtain a desired trajectory, jumping height and to be able to optimize jumping on slippery surfaces or compliant substrates. 


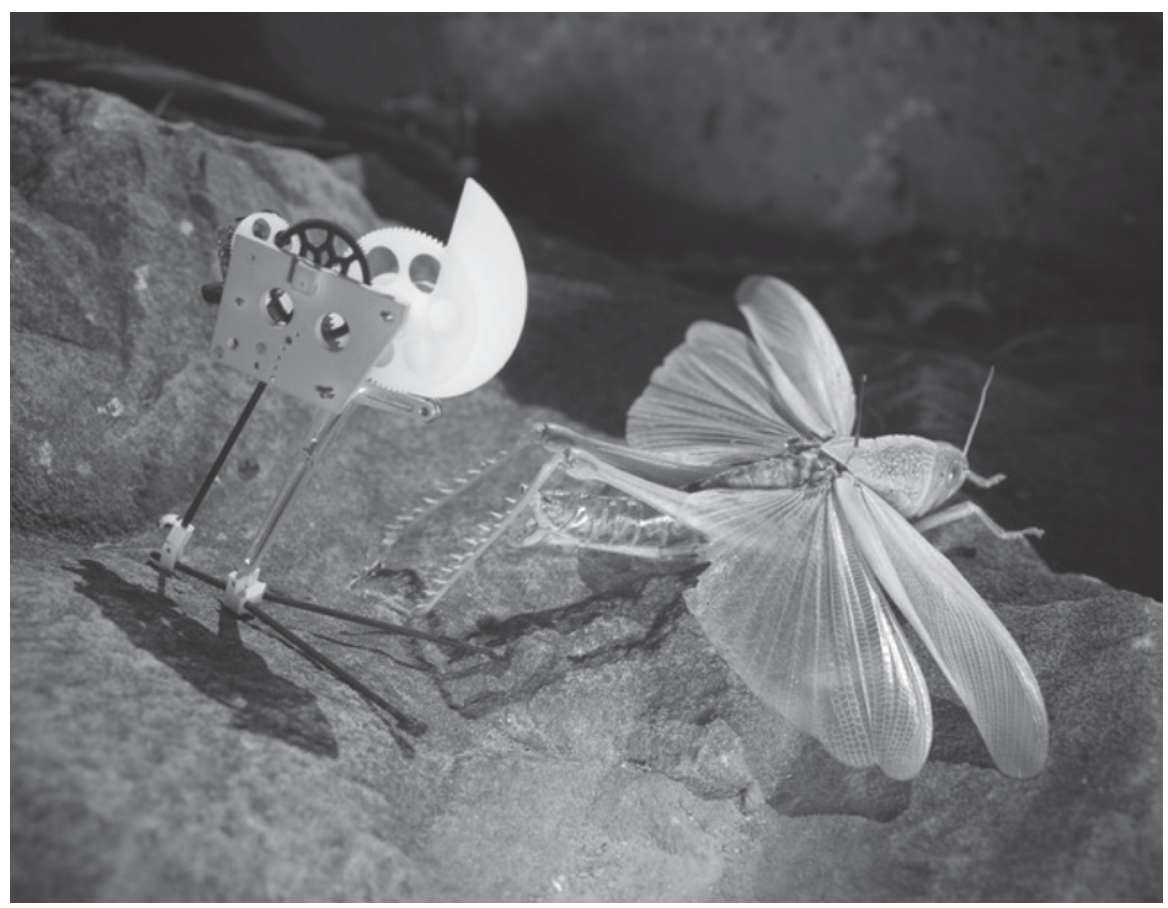

Fig. $117 \mathrm{~g}$ jumping robot prototype capable of clearing obstacles of up to $1.4 \mathrm{~m}$ height along with a desert locust using the same biomechanical design principle for jumping.
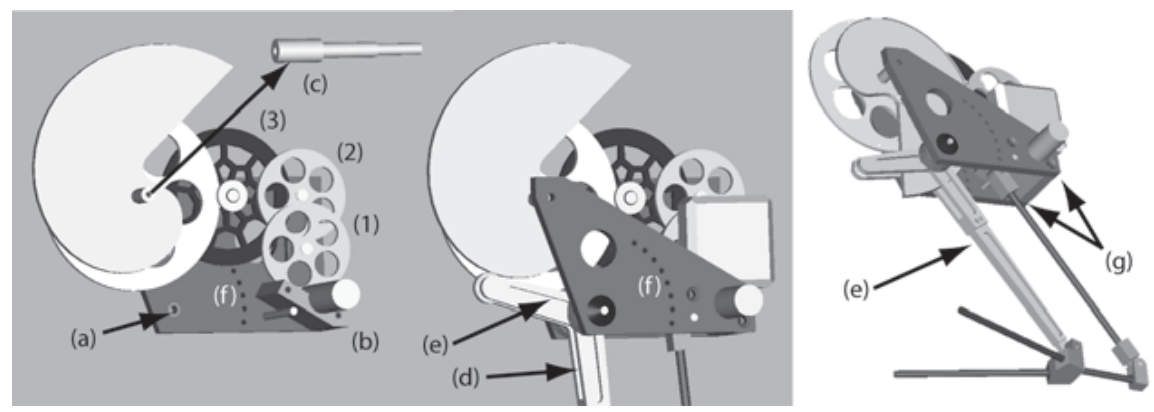

Fig. 12 CAD model of the gearbox. (a) brass bearing to reduce friction, (b) distance piece to align the two body plates, (c) cam axis, (d) slot in main leg for the cam, (e) main leg, (f) series of holes for spring setting and (g) the two body plates. (1),(2) $0.2 \mathrm{~mm}$ Polyoxymethylene (POM) gears and (3) $0.3 \mathrm{~mm}$ POM gear. 
Table 3 State of the art on jumping robots with on board energy and control

\begin{tabular}{|l||l|l|l|l|}
\hline Name & mass [g] & $\begin{array}{l}\text { approx. jump } \\
\text { height [cm] }\end{array}$ & $\begin{array}{l}\text { jump height per } \\
\text { mass [cm/g] }\end{array}$ & $\begin{array}{l}\text { approx. jump } \\
\text { height per size [-] }\end{array}$ \\
\hline Rescue robot [54] & 2000 & 80 & 0.04 & 3.5 \\
\hline $\begin{array}{l}\text { Minimalist jump- } \\
\text { ing robot [1] }\end{array}$ & 1300 & 90 & 0.07 & 6 \\
\hline Jollbot [4] & 465 & 21.8 & 0.05 & 1.4 \\
\hline Glumper [4] & 700 & 50 & 0.23 & 3.2 \\
\hline Scout [49] & 200 & 35 & 0.18 & 3.5 \\
\hline Mini-Whegs [30] & 190 & 22 & 0.12 & 2.2 \\
\hline Grillo [46] & $8-80$ & 5 & $0.63-0.06$ & 1 \\
\hline $\begin{array}{l}\text { Jumping robot } \\
\text { presented here }\end{array}$ & $\mathbf{7}$ & $\mathbf{1 3 8}$ & $\mathbf{1 9 . 7 7}$ & $\mathbf{2 7 . 6}$ \\
\hline
\end{tabular}

It has been shown [3][6][44] that at small size it is most advantageous to slowly charge an elastic element, release it with a click mechanism and amplify the take-off velocity using the legs as catapults, rather than applying a squad or countermovement jump. This principle is used by most of the small jumping animals such as frogs [44], desert locusts [6], stick insects [14], froghoppers [13], click beatles [3] or fleas [22]. We applied the same biomechanical design principles and were capable of achieving a very high jumping performance compared to existing jumping robots (table 3).

By changing the proportions of the four bar leg mechanism (figure 13) we can generate different foot tip trajectories, which translates to different ground force profiles, acceleration times and take-off angles depending on which length is changed. The amount of energy that will be stored in the springs can be adjusted between $106 \mathrm{~mJ}$ and $154 \mathrm{~mJ}$ in steps of $6 \mathrm{~mJ}$, by changing the spring setting (figure 12, f). The two body plates (figure 12, g) consist of a material called Cibatool, which is commonly used for rapid prototyping, can be easily machined and has low weight. The cam and gears are manufactured from Polyoxymethylene (POM) due to its low weight and low surface friction coefficient. For critical structural parts in the body and legs we used Polyetheretherketone (PEEK) due to its very high strengthto-weight ratio. Table 4 presents the weight budget of the robot. The entire and fully functional remote controlled prototype weights $6.98 \mathrm{~g}$ in its current form. Further weight reduction could be achieved by optimizing the two body plates, e.g. by drilling additional holes in it, and by using a smaller infrared receiver and battery.

Figure 14 depicts a complete take-off sequence of the jumping prototype including a payload of $3 \mathrm{~g}$ on top of the $7 \mathrm{~g}$ prototype. In order to illustrate the adaptability of the jumping force, figure 15 shows the jumping trajectories that were extracted from high speed movies for the jumping robot without, and with, a payload of $3 \mathrm{~g}$. The maximal height obtained without additional payload was $138 \mathrm{~cm}$. The acceleration time was $15 \mathrm{~ms}$, the initial take-off velocity $5.96 \mathrm{~m} / \mathrm{s}$ and the velocity at the top $0.9 \mathrm{~m} / \mathrm{s}$. The complete jump duration is $1.02 \mathrm{~s}$ and the traveled distance $79 \mathrm{~cm}$ at 
Table 4 Weight budget of the jumping robot

\begin{tabular}{|c||c|c|}
\hline Part & material & weight [g] \\
\hline \hline Body frame & Cibatool/PEEK & 1.4 \\
\hline Cam & POM & 0.78 \\
\hline Gears & POM & 0.63 \\
\hline Main leg & Aluminium & 0.76 \\
\hline Plastic parts on leg & PEEK/Carbon & 0.32 \\
\hline Screws and axis & Steel/brass & 0.79 \\
\hline 2 springs & Spring steel & 0.41 \\
\hline Motor & & 0.65 \\
\hline \hline Total mass mechanism & & $\mathbf{5 . 7 4}$ \\
\hline \hline LiPo Battery & & 0.48 \\
\hline IR receiver & & 0.76 \\
\hline \hline Total mass prototype & & $\mathbf{6 . 9 8}$ \\
\hline
\end{tabular}

a take-off angle of $75^{\circ}$. This means that the prototype presented here is capable of overcoming obstacles of more than 27 times its own body size.

The motor recharges the mechanism for one jump cycle in $3.5 \mathrm{~s}$. Using a $0.48 \mathrm{~g}$ LiPo battery, it thus allows for approximately 108 jumps.

\section{System Integration}

The next step is to combine the jumping mechanism with the wing folding system in order to allow the robot to jump and unfold the wings at the top of the jumping trajectory. This however, poses a number of integration challenges related to actuation and dynamics of the complete system. Figure 16 depicts a CAD model of a possible integration of the two mechanism. The gear (figure 10, c and 16, a) from the wing folding mechanism is interfaced with the third stage of the gear systems of the jumping mechanism (figure 12, 3 and 16, b). While charging the legs for jumping, this coupled system folds also the wings. Once the robot takes off, the wings are opened by the SMA-based release mechanism as described in section 2.2. Here, an important challenge is to define the time to unfold the wings. Since the forces acting on the system are very small at the top of the jump trajectory, it is difficult to precisely determine when it is best to unfold the wings. A possible solution may be to just assume a time constant when to open the wings after take-off. However, this integration of the wing folding and the jumping mechanism still has the limitation 

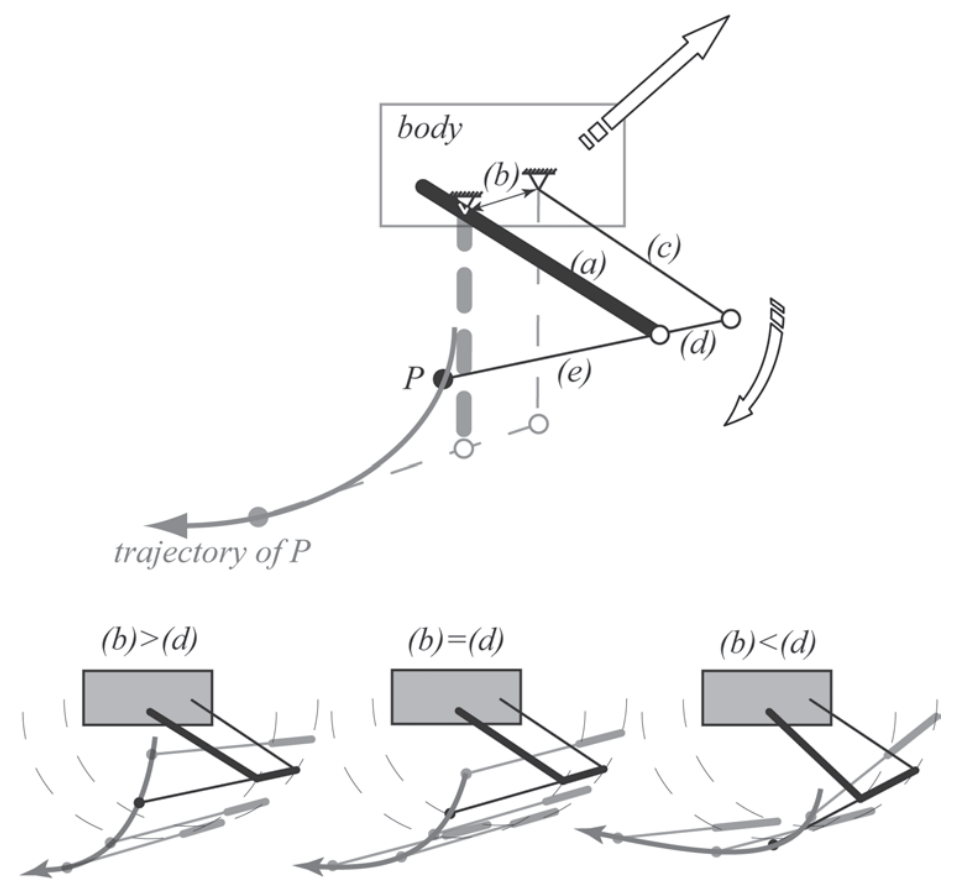

Fig. 13 Sketch of the four bar linkage jumping design and the foot tip P trajectory during takeoff. (a) is the input link and (b) the ground link. Changing the length of these four bars allows to adjust the take-off angle (change distance (e)), acceleration time (change distance (a) and (c)) and trajectory of the foot tip $\mathrm{P}$ (change ratio (b)/(d).

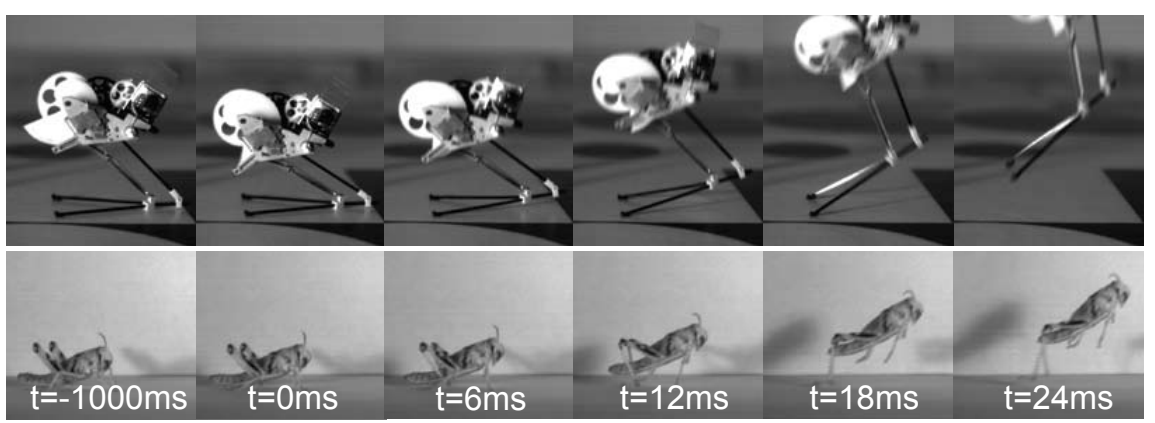

Fig. 14 Take-off sequence of our jumping robot compared to a desert locust. 

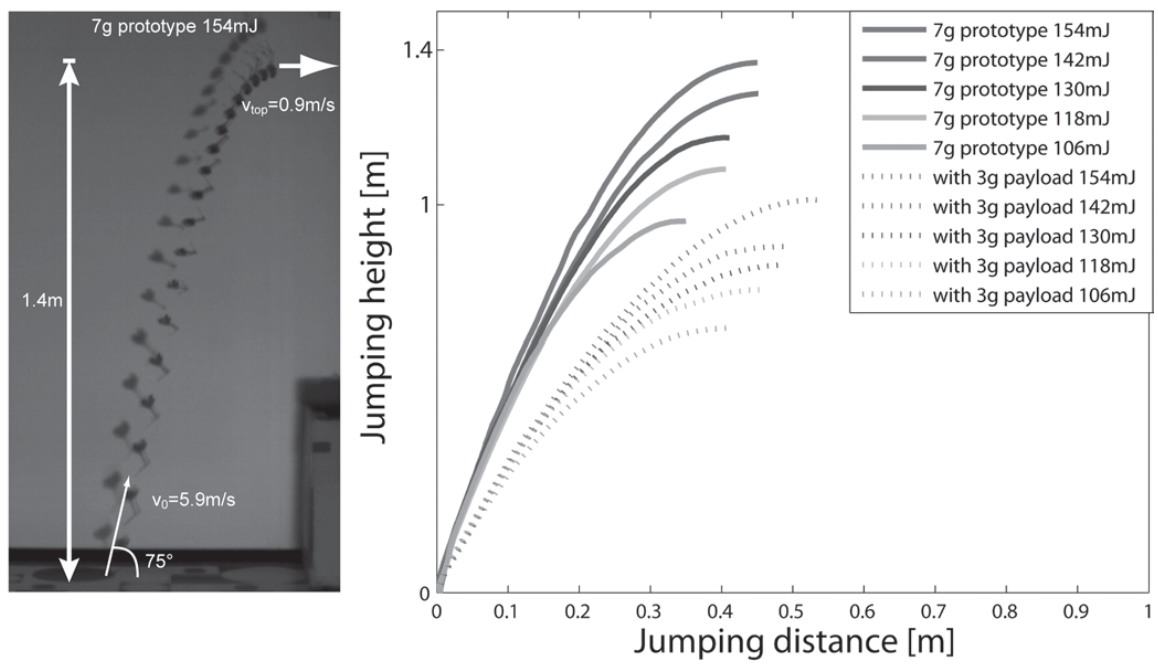

Fig. 15 Jump trajectory at different spring settings for the prototype with and without an additional payload of $3 \mathrm{~g}$.

that the attitude of the glider on top of the jump has to be upright in order to permit the robot to recover and perform stable gliding flight. Future work addresses the question how to recover from any position in air and ensure a proper transition to the subsequent gliding phase.

\section{Conclusion}

In this chapter, we highlighted jumping and gliding as a promising locomotion strategy to move across rough terrain. Although there still remain challenges in the integration of the components that a self-deploying microglider will need, the three subsystems described here may also be used as standalone platforms. For example, the jumping prototype could be equipped with an uprighting mechanism, a small communication unit, and sensors such as cameras or chemical sensors to perform environmental or security monitoring. The gliding system may also be equipped with sensors and launched from the roof of buildings or from airplanes to monitor the environment. The wing folding mechanism may allow the robot to be thrown high in the air by hand or by a catapult system.

Biological systems were a useful source of inspiration; For example, the wing folding mechanism adopts the mechanical principle from bats to fold the wings, which leads to a very light weight, simple and stable wing folding mechanism. Another example of direct biological inspiration is the jumping robot which, in the same way as e.g. locusts or fleas, first slowly charges an elastic element in the legs and then releases it quickly using a click mechanism to perform a catapult jump. On 


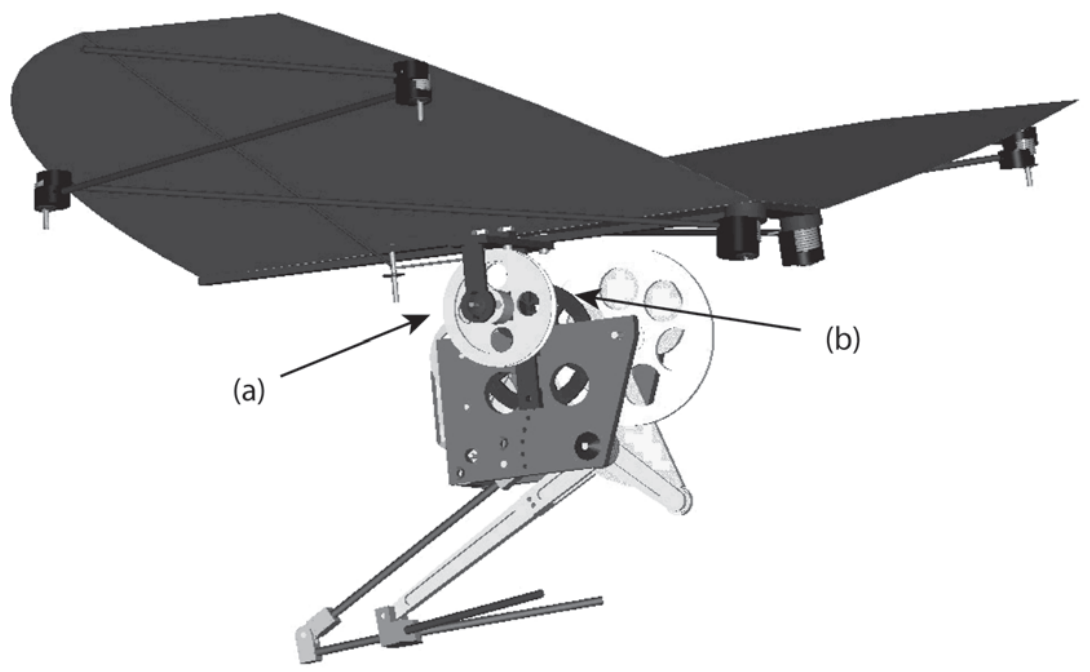

Fig. 16 CAD model of a possible integration of the subsystems. The gear from the wing folding mechanism (a) is interfaced with the third stage of the gear system of the jumping mechanism (b). While charging the legs for jumping, it also folds the wings which it can release on command on top of the jumping trajectory.

the other hand, such a robot may also be used as a physical model to test models of jumping and gliding in nature. The parameters that can be adjusted in our robotic platform include (i) the mass, (ii) the strength of the motor and spring in the jumping mechanism, (iii) the ground force profile during the acceleration phase of jumping, (iv) the leg length and flexibility, (v) the wing size and shape and (vi) the coordination between the jumping and wing folding subsystems, e.g. when to open the wings and how to stabilize and recover. By modifying these parameters, scale effects, such as the interplay between mass and size, of jumping animals can be investigated. The way in which the addition of wings affects jumping performance and the distance traveled per energy unit may also give insight in the evolution of flight.

Acknowledgements The authors would like to thank Martin Fuchs and Gregory Savioz for their significant contribution in the development of the wing folding mechanism and the jumping robot. Also we would like to thank the Atelier de l'Institut de production et Robotique (ATPR), especially Jean-Jacques Crausaz and Pascal Zbinden for their competent advice and endurance in the iterative fabrication process. Many thanks to Jean-Daniel Nicoud from www.didel.ch and André Guignard for the fruitful discussions and help with mechanical challenges. This project is funded by EPFL and by the Swiss National Science Foundation, grant number 200021-105545/1. 


\section{References}

1. Info-sheet No. 13, Nitinol Alloy Types, Conditions and Surfaces. URL http://www.memorymetalle.de

2. Micro flyer radio. URL http://www.microflierradio.com

3. Alexander, R.M.: Principles of Animal Locomotion. Princeton University Press (2003)

4. Armour, R., Paskins, K., Bowyer, A., Vincent, J.F.V., Megill, W.: Jumping robots: a biomimetic solution to locomotion across rough terrain. Bioinspiratoin and Biomimetics Journal 2, 65-82 (2007)

5. Azuma, A.: The Biokinetics of Flying and Swimming. American Institute of Aeronatics and Astronautics (2006)

6. Bennet-Clark, H.C.: The energetics of the jump of the locust schistocerca gregaria. Journal of Experimental Biology 63(1), 53-83 (1975)

7. Bishop, K.L.: The relationship between 3-d kinematics and gliding performance in the southern flying squirrel, glaucomys volans. Journal of Experimental Biology 209(4), 689-701 (2006)

8. Boria, F.J., Bachmann, R.J., Ifju, P., Quinn, R., Vaidyanathan, R., Perry, C., Wagener, J.: A sensor platform capable of aerial and terrestrial locomotion. In: 2005 IEEE/RSJ International Conference on Intelligent Robots and Systems, 2005. (IROS 2005), pp. 3959-3964 (2005)

9. Braitenberg, V.: Vehicles - Experiments In Synthetic Psychology. The MIT Press, Cambridge, MA (1984)

10. Brodsky, A.K.: The Evolution of Insect Flight. Oxford University Press (1996)

11. Burdick, J., Fiorini, P.: Minimalist jumping robot for celestial exploration. The Internation Journal of Robotics Research 22(7), 653-674 (2003)

12. Buri, H., Weinand, Y.: ORIGAMI - folded plate structures, architecture. In: 10th World Conference on Timber Engineering (2008)

13. Burrows, M.: Biomechanics: Froghopper insects leap to new heights. Nature 424(6948), 509

14. Burrows, M., Wolf, H.: Jumping and kicking in the false stick insect prosarthria teretrirostris: kinematics and motor control. Journal of Experimental Biology 205(11), 1519-1530 (2002)

15. Byrnes, G., Lim, N., Spence, A.: Take-off and landing kinetics of a free-ranging gliding mammal, the malayan colugo (galeopterus variegatus) (2008)

16. Coyle, F.A., Greenstone, M.H., Hultsch, A.L., Morgan, C.E.: Ballooning mygalomorphs: Estimates of the masses of sphodros and ummidia ballooners(araneae: Atypidae, ctenizidae). Journal of Arachnology 13(3), 291-296 (1985)

17. Davenport, J.: Allometric constraints on stability and maximum size in flying fishes: Implications for their evolution. Journal of Fish Biology 62, 455-463 (2003)

18. Dudley, R., Byrnes, G., Yanoviak, S.P., Borrell, B., Brown, R.M., McGuire, J.A.: Gliding and the functional origins of flight: Biomechanical novelty or necessity? Annu. Rev. Ecol. Evol. Syst 38, 179-201 (2007)

19. Dyke, G.J., Nudds, R.L., Rayner, J.M.V.: Flight of sharovipteryx mirabilis: the world's first delta-winged glider. Journal of Evolutionary Biology 19(4), 1040-1043 (2006)

20. Emerson, S.B., Koehl, M.A.R.: The interaction of behavioral and morphological change in the evolution of a novel locomotor type:" flying" frogs. Evolution 44(8), 1931-1946 (1990)

21. Entwistle, J.P., Fearing, R.S.: Flight simulation of a 3 gram autonomous glider (2006)

22. Gronenberg, W.: Fast actions in small animals: springs and click mechanisms. Journal of Comparative Physiology A: Sensory, Neural, and Behavioral Physiology 178(6), 727-734 (1996)

23. Haas, F., Gorb, S., Wootton, R.J.: Elastic joints in dermapteran hind wings: materials and wing folding. Arthropod Structure and Development 29(2), 137-146 (2000)

24. Haas, F., Wootton, R.J.: Two basic mechanisms in insect wing folding. Proceedings: Biological Sciences 263(1377), 1651-1658 (1996)

25. Jusufi, A., Goldman, D.I., Revzen, S., Full, R.J.: Active tails enhance arboreal acrobatics in geckos. Proceedings of the National Academy of Sciences 105(11), 4215-4219 (2008) 
26. Kaspari, M., Weiser, M.D.: The sizegrain hypothesis and interspecific scaling in ants. Functional Ecology 13(4), 530-538 (1999)

27. Keennon, M.T.: Muscle Wire Technology for Micro and Indoor Models (2004)

28. Kovac, M., Fuchs, M., Guignard, A., Zufferey, J., Floreano, D.: A miniature 7g jumping robot (2008)

29. Kovac, M., Guignard, A., Nicoud, J.D., Zufferey, J.C., Floreano, D.: A 1.5g sma-actuated microglider looking for the light. In: IEEE International Conference on Robotics and Automation, pp. 367-372 (2007)

30. Lambrecht, B.G.A., Horchler, A.D., Quinn, R.D.: A small, insect-inspired robot that runs and jumps. In: International Conference on Robotics and Automation, pp. 1240- 1245 (2005)

31. Li, P.P., Gao, K.Q., Hou, L.H., Xu, X.: A gliding lizard from the early cretaceous of china. Proceedings of the National Academy of Sciences 104(13), 5507 (2007)

32. Macia, S., Robinson, M.P., Craze, P., Dalton, R., Thomas, J.D.: New observations on airborne jet propulsion (flight) in squid, with a review of previous reports (2004)

33. Mahadevan, L., Rica, S.: Self-organized origami. Science 307(5716), $1740 \quad$ (2005). $\quad$ DOI 10.1126/science.1105169. URL http://www.sciencemag.org/cgi/content/abstract/307/5716/1740

34. Maynard Smith, J.: The importance of the nevous system in the evolution of animal flight. Evolution 6(1), 127-129 (1952)

35. McCay, M.G.: Aerodynamical stability and maneuvrability of the gliding frog polypedates dennysi. Journal of Experimental Biology 204, 2817-2826 (2001)

36. McGuire, J.A.: Allometric prediction of locomotor performance: an example from southeast asian flying lizards. The American Naturalist 161(2), 337-9

37. McGuire, J.A., Dudley, R.: The cost of living large: Comparative gliding performance in flying lizards (agamidae: Draco). The American Naturalist 166(1), 93-106 (2005)

38. Meng, J., Hu, Y., Wang, Y., Wang, X., Li, C.: A mesozoic gliding mammal from northeastern china. Nature 444, 889-893

39. Norberg, U.M.: Bat wing structures important for aerodynamics and rigidity (mammalia, chiroptera). Zoomorphology 73(1), 45-61 (1972)

40. Norberg, U.M.: Vertebrate Flight: Mechanics, Physiology, Morphology, Ecology and Evolution (1990)

41. Oliver, J.A.: "gliding" in amphibians and reptiles, with a remark on an arboreal adaptation in the lizard, anolis carolinensis carolinensis voigt. The American Naturalist 85(822), 171-176 (1951). URL http://www.jstor.org/stable/2457833

42. Paskins, K.E., Bowyer, A., Megill, W.M., Scheibe, J.S.: Take-off and landing forces and the evolution of controlled gliding in northern flying squirrels glaucomys sabrinus. Journal of Experimental Biology 210(8), 1413 (2007)

43. Pellegrino, S.: Deployable Structures (2002)

44. Roberts, T.J., Marsh, R.L.: Probing the limits to muscle-powered accelerations: lessons from jumping bullfrogs. Journal of Experimental Biology 206(15), 2567-2580 (2003)

45. Santer, R., Simmons, P., Rind, F.C.: Gliding Behaviour Elicited by Lateral Looming Stimuli in Flying Locusts. Journal of Comparative Physiology 191(1), 61-73 (2004)

46. Scarfogliero, U., Stefanini, C., Dario, P.: Design and development of the long-jumping" grillo" mini robot. In: IEEE International Conference on Robotics and Automation, pp. 467-472 (2007)

47. Socha, J., LaBarbera, M.: Effects of Size and Behavior on Aerial Performance of two Species of Flying Snakes (Chrysopelea). The Journal of Experimental Biology 208, 1835-1847 (2005)

48. Socha, J., O'Dempsey, T., LaBarbera, M.: A 3-d kinematic analysis of gliding in a flying snake, chrysopelea paradisi. Journal of Experimental Biology 208(10), 1817-1833 (2005)

49. Stoeter, S.A., Rybski, P.E., Papanikolopoulos, N.: Autonomous stair-hopping with scout robots. In: IEEE/RSJ International Conference on Intelligent Robots and Systems, vol. 1, pp. 721-726 (2002)

50. Suter, R.B.: Ballooning: data from spiders in freefall indicate the importance of posture. Journal of Arachnology 20(2), 107-113 (1992) 
51. Templin, R.J.: The spectrum of animal flight: insects to pterosaurs. Progress in Aerospace Sciences 36(5-6), 393-436 (2000)

52. Thomas, A.L.R., Jones, G., Rayner, J.M.V., Hughes, P.M.: Intermittent gliding flight in the pipistrelle bat (pipistrellus pipistrellus)(chiroptera: Vespertilionidae). Journal of Experimental Biology 149(1), 407-416 (1990)

53. Thompson, D.: On growth and form (1992)

54. Tsukagoshi, H., Sasaki, M., Kitagawa, A., Tanaka, T.: Design of a higher jumping rescue robot with the optimized pneumatic drive. In: IEEE International Conference on Robotics and Automation, pp. 1276-1283 (2005)

55. Vincent, J.F.V.: Deployable Structures in Biology, pp. 23-40. Springer (2003)

56. Wood, R., Avadhanula, S., Steltz, E., Seeman, M., Entwistle, J., Bachrach, A., Barrows, G., Sanders, S., Fearing, R.: Design, fabrication and initial results of a $2 g$ autonomous glider. In: IEEE Industrial Electronics Society 2005 Meeting, Raleigh North Carolina (2005)

57. Yanoviak, S., Dudley, R., Kaspari, M.: Directed Aerial Descent in Canopy Ants. Nature 433, 624-626 (2005)

58. Yanoviak, S.P., Dudley, R.: The role of visual cues in directed aerial descent of cephalotes atratus workers (hymenoptera: Formicidae). Journal of Experimental Biology 209(9), 17771783 (2006)

59. Young, B.A., Lee, C.E., Daley, K.M.: On a flap and a foot: Aerial locomotion in the "flying" gecko, ptychozoon kuhli. Journal of Herpetology 36(3), 412-418 (2002)

60. Zufferey, J.C., Floreano, D.: Fly-inspired visual steering of an ultralight indoor aircraft. IEEE Transactions on Robotics 22, 137-146 (2006) 